\title{
Ancylostomaduodenale and Ascarislumbricoides Mixed Infection in Pregnant Woman in Maharashtra
}

\author{
D.O.I - 10.51201/Jusst12526
}

http://doi.org/10.51201/Jusst12526

1. Mrs. PritiKaradbhajne

Research Assistant, Research \& Development,

DattaMeghe Institute of Medical Sciences, Sawangi (M), Wardha.

2. Mr. Anil Tambekar

Junior Research fellow, Research \& Development,

DattaMeghe Institute of Medical Sciences, Sawangi (M), Wardha.

\section{Dr. AbhayGaidhane}

School of Epidemiology and Public Health

DattaMeghe Institute of Medical Sciences, Sawangi (M), Wardha,

4. Dr. ZahiruddinQuazi Syed (Corresponding author)

School of Epidemiology and Public Health

DattaMeghe Institute of Medical Sciences, Sawangi (M), Wardha,

\section{Dr. ShilpaGaidhane}

Associate professor ${ }_{2} \mathrm{JNMC}$,

DattaMeghe Institute of Medical Sciences, Sawangi (M), Wardha.

\section{Dr. Manoj Patil}

Research Consultant, JNMC,

DattaMeghe Institute of Medical Sciences, Sawangi (M), Wardha, India;

\begin{abstract}
:
Background: More susceptible helminthic infection decreases immunodeficiency in pregnancy and may pose a serious threat to health and sometimes fatal to the new-born baby also. Ancylostomaduodenale and Ascarislumbricoides are categorized as soil-transmitted helminths. These helminths lead to greater impairment of mental and physical development, mainly in developing nations. Due to the shortage of qualified staff and suitable technology, these infections remain hidden and asymptomatic.Furthermore, sporadic shedding of eggs or larvae makes it tough to diagnose. There is, therefore, a desperate necessity of fast and precise tests to diagnose soil-
\end{abstract}


transmitted helminths. Microscopy and molecular approaches are included in the diagnostic methods.In countries where faeces are used as fertiliser and in the absence of sewage systems, these parasites are commonly observed, especially in tropical and subtropical areas.Case Presentation: A woman was enrolled in field survey DMIMS, Sawangi in July, 2017. The community-based field survey was held within four villages of district Wardha. A 22-year-old pregnant woman had a lot of complaints and history also. Symptoms correlated with electrolyte imbalance was seen. For detection purpose, microscopy and qPCR has been used in the case. Conclusion: The purpose of this study is to find out the reasons why pregnant women are more likely to get sick and to investigate the hygiene conditions in houses and evaluate the demographic feature. Throughout childhood to adulthood, a pregnant woman was malnourished. It is assumed from a study that the effect of under-nutrition may persist throughout life. A molecular technique like q PCR gives the most accurate results for infection. Keywords: Ancylostomaduodenale, Ascarislumbricoides, Mixedinfection, Pregnant woman, Helminths

\section{Introduction:}

Approximately billion of people are infected with intestinal helminths globally. India shares $21 \%$ of global parasitic infections. [1]STH is considered a neglected tropical disease due to reasons like high prevalent in underdeveloped countries, chronic illness, the burden for education and economy. [24]Soil-transmitted helminth includes Roundworm (Nematoda), Hookworm (Ancylostomaduodenale), and Whipworm (Trichuristrichiura) and some amoebic parasites i.e. Entamoebahistolytica and Giardia lamblia. [5,6] Soil-transmitted helminths as single or mixed infection causes death rarely but affects the nutritional status and functions of the body like metabolism, digestion, etc.[7]The nutritional deficiencies provoke malnutrition, leading to anemia, which affects physical and mental development in pregnant women and children. [8]Prevention of transmission of STHs could happen through the avoidance of practices such as the use of human feces as manure in farms, open defecation and could help the development of proper animal sewage disposal systems. [9]

Diagnostic tests can accurately and sensitively detect infections are essential information to the success of STH control programs. WHO recommended the Kato-Katz method for primary 
identification and q PCR for confirmation can use mostly. A molecular technique like q PCR shows accuracy in results.[3,10]

Hygiene conditions checked during the village survey were poor including hand washing materials, waste bin, and poor sanitary conditions. A woman was using unwashed fruit and vegetables directly from the farm to eat. She used to eat raw vegetables and drinking water from a pipe or on the other hand open natural pond on a routine basis. The family lived in bad conditions and poor hygiene. The family was living in a precarious financial situation and they did not make consultations or medical investigations. A woman was suffering from weakness and difficulty in breathing from childhood.

In the case of children and pregnant women, the parameter like height, weight, hemoglobin, cognition, mortality, etc have to be checked in case of soil-transmitted helminths. STH prevalence is more common in rural areas than in urban areas. Kind of work and health-related habits become responsible for infection of both geo-helminths.

\section{Case presentation:}

A field survey was conducted under the public health program by DMIMS, Sawangi, Wardha in four talukas of the district in May 2017. The trained social worker was appointed to survey rural areas. The trained social worker and the team were equipped and trained for the collection of a blood sample and transportation up to the laboratory. Basic data was collected by using a tablet questionnaire. It includes family background, income status, number of family members, and their education.

Patient information: A 23-year-old pregnant woman in 1st trimester was enrolled in the field survey. The previous history was taken about helminthic infection and anti-helminthic treatment. The woman complains about abdominal pain, burning sensation, and frailty since 7 days. From childhood to the young stage, weight increase was gradual. Hemoglobin fluctuation was observed in past lab reports. From her childhood, the woman was always sick and taking medicine. She has difficulty in breathing. There was no surgical history.

The woman was working in the field, cowshed. The woman was doing household work with cleaning of cowshed. She was not wearing footwear inside as well as outside of house.Her family was the 
below poverty line with Verbal informed consent was taken from the pregnant woman. The survey team gave knowledge to pregnant women about helminthic infection, how it causes infection to humans, health education, precaution, and stool sample collection. The survey team asked woman to provide their early morning stool sample in the container for helminthic examination. Our team provided her stool containers, gloves for collection purposes. Field social worker collected the stool and blood sample and transferred to the laboratory instantly by maintaining a cold chain using an ice pack.

Diagnostic assessment: The primary investigationconcluded with the microscopy for the identification of eggs from a stool sample. DNA extraction performed and q PCR confirmed the result of microscopy. The molecular technique gives accuracy for the result.

Microscopy: The wet mount microscopy carried out for the detection of helminthic parasitic infection. The iodine and saline wet mount technique was used, a small amount of stool sample in one to two drop of saline which is placed on a clean glass slide, after proper mixing coverslip was placed on the top of the slide with taking care of there will be no bubble in between glass slide and coverslip. The smear observance performed under a conventional microscope. Stool microscopy performed by using a wet mount staining test. The result of the Microscopy test was false positive because egg or worm does not see clearly.

Blood test: The blood sample shifted immediately to our laboratory with precaution. The hemoglobin was $7 \mathrm{~g} / \mathrm{dl}$. A woman was advised to admit in hospital for further tests of anemia. This interprets that infection of Ancylostomaduodenale and Ascarislumbricoides may become a reason for anemia.

DNA Extraction and RT-PCR: DNA extraction was carried out using Hi-Media stool DNA Kit. Realtime PCR was done by using the ITS region sequence probe for Ancylostomaduodenale and Ascarislumbricoides. The 20 $\mu 1$ reaction mixture contains 1x Tag man mixture, forward primer, reverse primer, probe, nuclease-free water, DNA. RT-PCR confirmed the mixed infection of Ancylostomaduodenale and Ascarislumbricoides in case. The reaction curve graph 
of Real-Time PCR assay is shown in the figure. RT-PCR gave a positive result for the infection of Ancylostomaduodenale and Ascarislumbricoides.

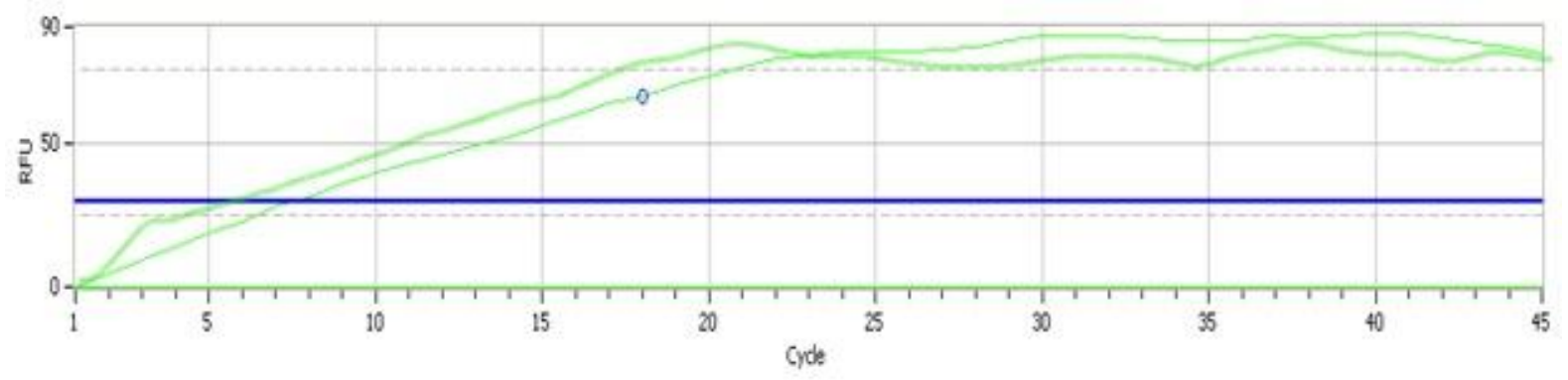

Fig: Reaction curve graph of RT-PCR assay of mixed infection of A. duodenale and $A$.

\section{lumbricoides.}

A woman was advised for treatment to DMIMS hospital.The regular visit to their household was done, after 2 months of observation; there was no complaint of any kind of pain and breathing difficulty.

\section{Discussion:}

Efforts to introduce usage of pit-latrines instead of open defecation become a small step against parasitic infection. The personal hygiene habits i.e. washing hands with soap before eating, after defecation, washing fruits before eating, footwear when outdoors, etc has been introduced by social worker. Anaemia having pregnant women with parasitic infection can be cure alongside consumption of nutritious food. Pregnant women had significant risk of bathing outside the house or lack of information of the effect of soil-transmitted helminths.

The village was lack of facilities of sanitation, drinking water supply. Themost of the population was unknown of hand hygiene habit. The economic status of villagers is poor due to infertility of soil. Half of the population was taking bath outside of the house and use to go for open defecation. The pregnant woman was poor and neglected health from childhood due to low-income source of family.

Real time PCR is a molecular technique, whichwas used in our case study. RT PCR is a technique gives more specificity and sensitivity of result. This technique is expensive rather than other methods. RT PCR gives more accuracy in result than microscopy. 
The high prevalence of STHs has been associated with poverty, poor environmental hygiene, lack of adequate facilities for water supply and sanitation, ignorance, and impoverished health services.[1113] Another reason for prevalence is residential places where lifestyle poverty, poor housing conditions, and overcrowding are present. The poor sanitation practices include the use of traditional latrines, open field defecation, and the use of fecalcontaminated water to become the main source of intestinal parasitic infections in the people of such a remote area of India. [14-16]

There is low constancy between Ascarislumbricoides and Ancylostomaduodenale infection. In India, Ancylostomaduodenale prevalence may be high or moderate at any prevalence of Ascarislumbricoides.[17-19] National parasitological surveys describe that the frequency of infection for each parasite can differ broadly within a country. [20-23] The infection rate reveals from diagnosis and this rate describes the intensity of infection of the parasite. The species for Ancylostomaduodenale and Ascarislumbricoides can be identified easily from the morphology of adult worms, but sometimes identification becomes difficult by using the morphology of egg. $[8,17,23$, 24,25]

\section{Conclusion:}

It can be concluded that mixed infection cannot identify by microscopy. The molecular technique gives accuracy in the result. A pregnant woman did all type of household work related to soil. There is also a need to classify which work to do at home during pregnancy. The infection depends on the kind of work done by a pregnant woman. The physical condition of a pregnant woman was unfit. Her social environment and financial situation at home are linked to her pregnancy growth and diseases.

Informed Consent: Signed by Patient.

Conflict of Interest: Nil

Financial resource of the study: Public Health Foundation of India (PHFI)

PHRI funding Grand Number: IN-DL60331777444446P

Certificate Issued Date: 20 March 2017 


\section{References:}

1. Salam N, Azam S. Prevalence and distribution of soil-transmitted helminth infections in India. BMC Public Health. 2017 Dec;17(1):201.

2. Becker SL, Liwanag HJ, Snyder JS, Akogun O, Belizario. V, Freeman MC, et al. Toward the 2020 goal of soil-transmitted helminthiasis control and elimination. Bottazzi ME, editor. PLoS Negl Trop Dis. 2018 Aug 14;12(8):e0006606.

3. Tambekar A, Burnase N, Gaidhane A, Fulzele P, Syed Q. Comparison of two microscopic methods for the detection of parasitic infection in antenatal women in selected areas. 2020;8.

4. Borle R, Nimonkar P, Hingnikar P, Khatib MN, Gaidhane AM, Zahiruddin QS. Efficacy and safety of different interpositional flaps and grafts for closing fibrotomy wound in patients of oral submucosal fibrosis: A systematic review with meta-analysis. 2019;19.

5. Pabalan N, Singian E, Tabangay L, Jarjanazi H, Boivin MJ, Ezeamama AE. Soil-transmitted helminth infection, loss of education and cognitive impairment in school-aged children: A systematic review and meta-analysis. Budke CM, editor. PLoS Negl Trop Dis. 2018 Jan 12;12(1):e0005523.

6. Darlan DM, Winna M, Simorangkir HAH, Rozi MF, Arrasyid NK, Panggabean M. Soiltransmitted helminth and its associated risk factors among school-aged children. IOP Conf Ser: Earth Environ Sci. 2019 Jul 25;305:012066.

7. Augustine DL, Nazmi M, Helmy M, McGavran EG. The Ova-Parasite Ratio for Ancylostoma duodenale and Ascaris lumbricoides. The Journal of Parasitology. 1928 Sep;15(1):45.

8. Simarmata N, Sembiring T, Ali M. Nutritional status of soil-transmitted helminthiasisinfected and uninfected children. :6. 30 June; 2015.

9. Hung BK, De NV, Duyet LV, Chai J-Y. Prevalence of Soil-Transmitted Helminths and Molecular Clarification of Hookworm Species in Ethnic Ede Primary Schoolchildren in Dak Lak Province, Southern Vietnam. Korean J Parasitol. 2016 Aug 31;54(4):471-6.

10. Tambekar A, Burnase N, Gaidhane A, Fulzele P, Syed Q. Foldscope assisted microscopy for the examination of Soil Transmitted Helminths (STH). 2020;5.

11. Muznebin F, Khanum H, Hossain A. Incidence of Nematode Infections among the Children brought to ICDDR, B Hospital, Dhaka, Bangladesh. J bio-sci. 1970 Jan 1;15:159-64.

12. Pullan RL, Halliday KE, Oswald WE, Mcharo C, Beaumont E, Kepha S, et al. Effects, equity, and cost of school-based and community-wide treatment strategies for soil-transmitted helminths in Kenya: a cluster-randomised controlled trial. The Lancet. 2019 May;393(10185):2039-50.

13. Bamanikar S, Bamanikar A, Sawlani V, Pandit D. Gastroscopic diagnosis of ankylostoma duodenale infestation as a cause of iron-deficiency anemia. Med J DY Patil Univ. 2014;7(5):631.

14. Achanta C. Image Diagnosis: Gastric Migration of Hookworms in a Patient with Anemia. permj [Internet]. 2016 Jun 24 [cited 2020 May 21]; Available from: http://www.thepermanentejournal.org/issues/2016/summer/6181-image-diagnosis-gastric-migrationof-hookworm.html 
15. Bhatawadekar D. Hookworm Infestation in Infant: A Rare Case Report. : 1.

16. Baltz JG, Mishra R, Yeaton P. Unusual Case of Hookworm Presenting as Acute Surgical Abdomen. The American Journal of Medicine. 2009 Feb;122(2):e3-4.

17. Giraldo-Forero JC, Muñoz-Niño LA, Coronado-Castiblanco KV. Severe iron anemia deficiency caused by hookworm: Case report and literature review. HGMX. 2019 Oct 29;82(4):3102.

18. Khatib M, Sinha A, Gaidhane A, Simkhada P, Behere P, Saxena D, et al. A systematic review on effect of electronic media among children and adolescents on substance abuse. Indian $J$ Community Med. 2018;43(5):66.

19. Mohapatra S, Kumar A, Deb M, Sharma B. Diagnostic dilemma in hookworm infection: An unusual case report. Indian J Med Microbiol. 2015;33(1):179.

20. Booth M, Bundy DAP. Comparative prevalences of Ascaris lumbricoides, Trichuris trichiura and hookworm infections and the prospects for combined control. Parasitology. 1992 Aug;105(1):151-7.

21. Karadbhajane P., Tambekar A., Gaidhane A., Zahiruddin Z. Q., Gaidhane S., Patil M., Giardiasis in tropical region in the state of Maharashtra: case series. July-2020, https://doi.org/10.13140/RG.2.2.12686.18248

22. Puri S, Fernandez S, Puranik A, Anand D, Gaidhane A, Quazi Syed Z, et al. Policy content and stakeholder network analysis for infant and young child feeding in India. BMC Public Health. 2017 Jun;17(S2):461.

23. Thow AM, Karn S, Devkota MD, Rasheed S, Roy S, Suleman Y, et al. Opportunities for strengthening infant and young child feeding policies in South Asia: Insights from the SAIFRN policy analysis project. BMC Public Health. 2017 Jun;17(S2):404.

24. Karadbhajne, P., Tambekar, A., Gaidhane, A., Syed, Z. Q., Gaidhane, S., Patil, M., May (2020). Medical Science, Amoebiasis in pregnant woman : A case report. 24(104).

25. Pierce D, Merone L, Lewis C, Rahman T, Croese J, Loukas A, et al. Safety and tolerability of experimental hookworm infection in humans with metabolic disease: study protocol for a phase $1 \mathrm{~b}$ randomised controlled clinical trial. BMC Endocr Disord. 2019 Dec;19(1):136. 